\section{Environmental health or psychiatric rehabilitation}

Dear Editor - While most of us would agree that bacteriological, chemical, accident prevention and suicide prevention strategies need to be worked into our mental health as well as general hospital facilities, it has become quite clear that some of these measures are not appropriate in a domestic setting. An important part of rehabilitating clients of the psychiatric services is their training in activities of daily living. However it appears that the institutional standards are being generically applied to all institutions, no matter how small, sometimes to the severe disadvantage of psychiatric rehabilitation to the extent that it endangers the function of our day centres. We have recently had visits from environmental health officers who suggest that our clients should not have access to cooking knives, that they are only allowed to drink tea in a designated dining area, and that they have to follow the same complicated mop and bucket protocol as any large institution. This means that clients in residences may be left waiting for dinner as some tables are in kitchen areas in smaller residences, their clients will never be judged to be able to assist or take over cleaning and maintenance of their own living areas or kitchens, and will be prevented from either being able to prepare food properly or to handle normal living situations. Ultimately the effect of current environmental health legislation is that, rather than learning to live in a home, clients are learning to live in an institution, and their ability to substantially participate in the running of a home is being militated against.

Where local environmental health officers insist on following the letter of the law it appears there is no way for clients to improve their functioning in day centres or psychiatric residences unless some kind of derogation is made, especially for smaller staffed residences and day centres with ADL training. Perhaps we need to be reminded that 50 years ago clients were regularly involved in all kinds of 'dangerous' work, such as farm work, laundries, kitchens, shoe repair and tailoring facilities.

Séamus Ó Flaithbheartaigh Consultant Psychiatrist in Rehabilitation Services, St. Joseph's Hospital, Mulgrave Street, Limerick.

\section{The Norman centenary}

Dear Editor - The ministrations of Conolly Norman in the Richmond Asylum, Grangegorman, and the administrative load on medical superintendents in Irish asylums have recently been featured in the Journal. ${ }^{1,2}$ Perhaps space can be found for a brief biographical note on Doctor Norman in this his centenary year. The fifth son of Rev. Hugh Norman, he was born on March 12, 1853 at Newtown Cunningham, county Donegal, and was educated at home before he commenced the study of medicine in 1870 at the Carmichael School, Richmond Hospital and Trinity College Dublin. He qualified in 1874, proceeded FRCSI in 1874 and FRCPI in 1878 , and was conferred with an honorary MD in $1907 .^{3}$

From the time he qualified at the age of 21 he devoted himself to the study of mental diseases and served at Monaghan, Castlebar, and Monaghan again before he was appointed to the Richmond Asylum in 1888. 'He found the premier asylum a gloomy prison ... and he left it presenting the twofold aspect of a hospital and a hive of industry where the bodily strong found occupation and relief ... he was no mere administrator but essentially a physician'. He was widely versed in the continental literature and served as joint editor of the Journal of Mental Science. ${ }^{4}$

He used adversity in the shape of an epidemic of dysentery and outbreaks of beri-beri to rail against overcrowding, and succeeded in persuading the authorities to build an auxiliary asylum at Portrane - even while he argued that overcrowding could be alleviated by allowing harmless lunatics to be cared for outside in the community. In his presidential address to the Royal Medical Psychological Association in the Royal College of Physicians in January 1894 he bewailed the institutionalisation of staff as a result of unremitting care and toil with trivialities.

Norman suffered from angina pectoris for the last twelve years of his life. He developed influenza with bronchitis in December 1907, and only resumed duties on the Monday before his sudden death after walking a couple of hundred yards from his home on Sunday February 23, 1908.

Acknowledgements: Librarians Mary O'Doherty RCSI and Robert Mills RCPI very kindly tracked down the obituary notices for me.

C S Breathnach, School of Medicine and Medical Science, UCD, Belfield, Dublin 4

References

1. Kelly B D. One hundred years ago. The Richmond Asylum, Dublin, in 1907. Irish Journal of Psychological Medicine, 2007; 24: 108-114.

2. Walsh D. Care of the mentally ill in Ireland in 1901 - the vindication of a policy. Irish Journal of Psychological Medicine, 2007; 24: 132-139.

3. Anonymous. Obituary, Conolly Norman. BMJ, 1908; 1: 54

4. JMF. In Memoriam Conolly Norman. Dublin Journal of Medical Science, 1908125 316-322.

\section{Anti-psychotic poly- pharmacy and combined high-dose anti-psychotic prescribing in schizophrenia}

Dear Editor - Irish research in the areas of anti-psychotic poly-pharmacy (concomitant use of two or more antipsychotics) and combined high-dose anti-psychotic prescribing, in psychiatric inpatients, especially patients with schizophrenia, is important because of the evidence in the international literature about the dangers, prevalence, possible reasons for and legal significance of these sub-optimal prescribing practices. ${ }^{1,2}$

Our retrospective, non-randomised survey aimed to find the prevalence of: 1) anti-psychotic poly-pharmacy and 2) combined high-dose anti-psychotic prescribing, in patients with ICD-10 diagnosis of schizophrenia, in discharge prescriptions, in 50 consecutive discharges, from the 50 bedded acute adult psychiatric unit at Kerry General Hospital, in the year 2004 
The sample included: $33(66 \%)$ males and 17(34\%) females. Male to female ratio was $2: 1$. The age range was; 18-69 years, $30(60 \%)$ were below 45 years of age. The admission legal status was; involuntary (temporary) in $15(30 \%)$ and voluntary (informal) in 35(70\%).

First admissions were $6(12 \%)$, and readmissions were $44(88 \%)$. Patient demographics are similar to that reported on a national level.

Results of this study found that of the 50 patients, six (12\%) were discharged on two or more anti-psychotics and of these two $(4 \%)$ were prescribed combined anti-psychotics exceeding the maximum licensed dose. There was predominant atypical anti-psychotic mono-therapy $82 \%(n=41)$, use of clozapine alone in $20 \%(n=10)$ and use of risperidone depot anti-psychotic in $20 \%(n=10)$.

The main conclusion of this study was that we could not find evidence that the high rates of anti-psychotic poly-pharmacy and combined high-dose prescribing reported in the international literature applied to this Irish sample.

This is a similar conclusion to a previous study in Cork by I Dixit et al, 2005, which had a bias toward a more urban population. ${ }^{3}$ It is possible that as financial restrictions on Irish consultants prescribing of clozapine are lower than in the UK and US, this minimises the practice of resorting to antipsychotic poly-pharmacy in treatment resistant and difficult to manage patients, where clozapine might be a better option. ${ }^{2}$ Risperidone depot formulation has only been available in Ireland since June 2003; that is after the study period of the much cited Canadian study and the possibility that its higher use is associated with lower prevalence of antipsychotic poly-pharmacy needs further exploration. ${ }^{1}$

Other explanations might be a greater awareness amongst Irish psychiatrists of the potential hazards of the practice and local factors.

The authors intend to expand the study and adopt a longitudinal format in an attempt to throw further light on this intriguing finding.

\section{Ajay Dixit}

Registrar in Psychiatry, Home Based Crisis Team, St Mary's Day Hospital, Mercy University Hospital,

Cork, Ireland

Darra Phelan

Consultant Psychiatrist, Kerry General Hospital, Tralee, Co Kerry, Ireland

\section{References}

1. Procyshyn R, Kennedy N, Tse G, Thompson B. Anti-Psychotic poly-pharmacy: a survey of discharge prescriptions from a tertiary care psychiatric institution. Can J Psychiatry 2001(May); 46: 334-339.

2. Lelliott P, Paton C, Harrington M, Konsolaki M, Sensky T, Okocha C. The influence of patient variables on poly-pharmacy and combined high dose of anti-psychotics prescribed for in-patients. Psychiatric Bull 2002; 26: 411-414

3. Dixit A, Corcoran F, Crowley-Barry N. Anti-psychotic poly-pharmacy: a survey of discharge prescriptions from an acute adult psychiatric unit in an lrish university hospital. Ir Psychiatrist 2005; Oct-Nov: 16-19.

\section{Core general adult psychiatry functional syndromes}

\section{O' Shea B. Eireann Healthcare Publications, 2007. 227 pps.}

Over the last few wet weeks in the sunny south east I have thoroughly enjoyed leafing my way through (my autographed copy of) the latest inspired offering from Brian O'Shea. Many Irish psychiatric clinicians are very familiar with the author and have already benefited for a modest number of years from four editions of his major volume $A$ Textbook of Psychological Medicine, 4th ed, Eireann Healthcare publications, 2002. For the uninitiated, Dr Brian O'Shea recently retired as clinical director and consultant psychiatrist at Newcastle Hospital, county Wicklow where he had worked since 1985. In addition to publishing major psychiatric textbooks, he has penned almost 400 journal articles and has extensive experience as an examiner in both parts of the MRCPsych examination. Brian is now editor of the journal Irish Psychiatrist and works part-time as a tribunal consultant psychiatrist for the Mental Health Commission.

It's not surprising therefore that this scholarly contribution will be of great interest to both trainees preparing for written and oral examinations, as well as more seasoned performers attempting to appraise themselves of the modern and historic understandings of the core functional syndromes that domi-

\section{Ir J Psych Med 2008; 25(1): 34-35}

nate our working lives. In his introductory preface the author offers this work as "a non-toxic source of up-to-date information that is digestible during an era of rapid change". This he has succeeded in doing.

As the textbook deals exclusively with non-organic conditions it consists of only eight clinical chapters:

1. Schizophrenia and other non-affective psychoses

2. Affective disorders and suicidal behaviour

3. Grief

4. Neuroses, somatoform and factitious disorders

5. Disorders of personality

6. Eating disorders

7. Child sexual abuse and its sequelae

8. Psychosexual medicine.

There are also two very useful non-clinical chapters:

9. A summary of $A$ Vision for Change

10. A summary of the 2001 Mental Health Act.

The book has authority for an international audience but is written with a particular Irish garnish, and cites modern home research and publications as well as useful non-Irish comparators. Each page has a series of referenced footnotes which expand in extraordinary detail on the facts/information elucidated in the main text. Therefore the work can be read as either a brief summary of the most pertinent facts on a topic, or as a major academic tome depending on the reader's motivation. Each chapter has user friendly headings including cost of the condition on society, epidemiology, aetiology, definitions, clinical features, treatments, prognosis and 